Interactive comment on "A weighted least squares approach to retrieve aerosol layer height over bright surfaces applied to GOME-2 measurements of the oxygen A band for forest fire cases over Europe” by Swadhin Nanda et al.

Anonymous Referee \#1

Received and published: 18 April 2018 


\section{Review of the manuscript 'A weighted least squares approach to retrieve aerosol layer height over bright surfaces applied to GOME-2 measurements of the oxygen A band for forest fire cases over Europe' by Nanda et al.}

April 18, 2018

The manuscript describes a method to retrieve aerosol layer height by dynamically modifying the measurement error covariance matrix for a weighted least square approach. The manuscript is well-organised and include description and verification of the modified retrieval method. The manuscript is acceptable for publication after consideration of the suggestions for changes given below.

- Page 4, line 6: It is stated that Raman scattering is ignored. The impact of rotational Raman scattering in the $\mathrm{O}_{2}$-A band has been quantified by Vasilkov et al. (2013). Please justify why you omit Raman scattering considering their results. Specifically, may Raman scattering significantly impact your dynamical scaling method? 
- Page 9, line 2: Please define LER.

- Page 9, line 14: Please remove 'seems to'. The formal approach does not 'seems to' retrieve more pixels, it actually does so.

- Page 10, line 13: Please quantify 'majority of the cases', for example by giving the percentage.

- Page 11, lines 22-24: These numbers are provided in Table 4 and need not to be repeated here. If you choose to repeat them, include a reference to Table 4.

- Page 11, line 32: Table 3 is first referenced after Table 4. Please rearrange.

- Page 13, line 5: What is your reason for stating that the 'values are not realistic'? The Moscow station may not be representative as the plume is thick and nonhomogeneous (manuscript page 12, line 14.) Have you compared the retrieved AOT values with MODIS AOT? That might shed light on how realistic the retrieved values are.

- Page 13, line 6: Please give the retrieved AOT values for the Moscow station pixel.

- Page 14, line 4: I would replace 'still unrealistic' with 'still high', but see also comment above for Page 13, line 5.

- Page 14, line 18: Please include reference to Table 5, that is, the sentence should end with: ' the 2010 fires is 0.19 , see Table 5.'

- Page 15, line 3: Please change 'is to profiles from a' to 'to profiles from a'.

- Page 16, line 23: Please change 'demonstrated over real' to 'demonstrated for real'. 
- Page 16, line 29: Please change 'improves' to 'increases'.

- Page 16, lines 31: Maybe change 'not realistic' to 'too high'?

AMTD

- Page 17, lines 19-22: Your algorithm retrieves AOT and ALH. Here you state that the AOT is not necessarily a realistic value, but rather a diagnostic quality measure. If the AOT is of diagnostic quality only, how can then the ALH be a realistic value when they both come from the same retrieval? The discussion about AOT over these lines is rather unclear and maybe it is better to just leave it out.

- Page 23, Fig. 3, caption: Please include overpass times for the MODIS images.

- Pages 24 and 27, Figs. 4 and 7: Please change colour scale range in Figs. 4b,d and $7 b, d$ so it agrees with the height ranges in Figs. $5 b$ and $5 d$, respectively. As they are, Figs. 4b,d and 7b,d do not show the height structure.

- Page 26, Fig. 6, caption: Please change 'attenated' to 'attenuated'.

- Page 28, Fig. 8, caption: The following sentences are repeated twice: 'The red and blue dashed line represents retrieved aerosol layer height using the formal approach and the dynamic scaling method, respectively. The red and blue shaded boxes represent the aerosol layer from the respective retrieval methods.'

\section{References}

- Vasilkov, A., Joiner, J., and Spurr, R.: Note on rotational-Raman scattering in the $\mathrm{O} 2 \mathrm{~A}$ - and B-bands, Atmos. Meas. Tech., 6, 981-990, https://doi.org/10.5194/amt-6-981-2013, 2013. 